\title{
An analysis of student performance in clinical appointment in forensic medicine
}

\author{
Mendis $A^{*}$, Perera J, Samaranayake R \\ Department of Forensic Medicine and Toxicology, Faculty of Medicine, University of \\ Colombo
}

*Corresponding author:Tel:0094-71-4415099.E-mail:ndnamendis@yahoo.co.uk

MLJSL.Vol 2. No 2. September. pp 32-38

\begin{abstract}
Introduction:

Undergraduate medical students have only one clinical attachment in forensic medicine during their entire curriculum. Within this time imparting a clinical skill is difficult before basic theory is taught.

\section{Objectives:}

To analyze the clinical and practical skills obtained during the clinical appointment and suggest changes to clinical appointment.

\section{Method:}

Medico-legal reports (MLR) and post mortem reports (PMR) written by ninety five undergraduates who followed the appointment before the completion of the medico-legal module were analyzed. Key sections were analyzed based on pre-determined criteria. A mark was allocated ranging from 1 (poor)5 (very good) by evaluating the criteria. Marks obtained for each criterion under a section analyzed were added to obtain a total mark. The average of the total mark for each section was again graded according to the same marking scheme.
\end{abstract}

\section{Results:}

In the reports analysed, for sections on basic information/identification and category of hurt, more than $70 \%$ of students obtained an acceptable mark, but for injury description it was $58 \%$. For opinion writing it was below $60 \%$. The success rate for writing a proper cause of death was $55 \%$.

\section{Conclusions:}

Even without basic forensic theory knowledge we have been able to train the students how to write an acceptable MLR and PMR but success rate for formulation of opinion and cause of death was not satisfactory. Therefore clinical teaching appointment should be well planned and placed in a proper position within the curriculum. The use of a structured time table is also important. It is important to give basic knowledge on forensic medicine prior to clinical training.

Key words: Undergraduate, Clinical appointment, Forensic Medicine, practical skills, Medico - legal report, Postmortem report 


\section{Introduction}

Forensic medicine is the medical specialty that is practiced at the interface of medicine with law. It involves the assessment and interpretation of findings in an individual who has become involved either as a victim or suspect in some form of alleged criminal action. However the role of practitioners of forensic medicine has widened to include civil jurisdictions as well. Forensic Medicine is a discipline taught in the curriculum of all medical faculties in Sri Lanka. Teaching forensic medicine in the undergraduate curriculum is important since the courts consider every M.B.B.S. qualified doctor as an expert in the field of legal medicine. Wide range of professionalism issues should be introduced to the students early in their career, and an array of opportunities should be provided for the student to experience these issues in practice[1]. This is best done during the clinical appointment. The Faculty of Medicine Colombo has a structured clinical appointment for the students where students are expected to work according to a time table with a teacher assigned to help and teach them.

However, the superior performance of most clinicians on the procedural as opposed to declarative questions is consistent with their having learned educational principles in the clinical setting[2]. Therefore, it is important to give basic knowledge on forensic medicine prior to clinical training. In spite of this, in the Faculty of Medicine Colombo, with curriculum changes to a module based teaching in 1995[3], students are currently assigned to do their clinical forensic medicine appointment before, during or after the medico-legal module. This results in students having different levels of knowledge coming to do the appointment.

\section{Objective}

1. Analyze the practical and clinical skills obtained during the clinical appointment.
2. Suggest the possible changes in structuring the clinical teaching schedule to improve competencies.

3. Suggest the possibility of changing the exact timing of the medico-legal appointment within the MBBS curriculum.

\section{Materials and Methods}

A selected sample of reports consisting of one medico-legal report (MLR) and 01 post mortem report (PMR), each written by ninety five undergraduates of the Faculty of Medicine Colombo who did their clinical appointment before the completion of the medico-legal module were analyzed retrospectively. Six key sections were analyzed based on predetermined criteria. The number of criteria varied from section to section.

Sections A - F are given below with the various criteria under each section.

A) Basic Information (MLR and PMR): 1. Case related specific information, 2. Personal information of the examinee, 3. Information about examination

B) History: 1. Relevancy of the information included, 2. Presence or absence of important information to the case, 3 .

Correct chronological order of events, 4.Use of medical terms

C) Injury description: 1. Clarity, 2.Use of technical/medical terms, 3.

Properdescription,4.Mentioning the type, 5. Size, $6 . \quad$ Location, mentioning associated findings 7.Numbering system.

D) Category of hurt: 1. Correct category, 2. Method of entry, $3 . \quad$ Inclusion of additional information.

E) Opinion in MLR: 1. method of entry. 2. Correctly filled. 3. Additional opinion included when necessary

F) Cause of death (PMR): 1. correct use of WHO classification method when relevant, 2. ??standard cause of death, 3. correct sequence from 1 (a) to 1 (c), 4. Correct filling of part 2 
Each of the above criteria under section $A-F$ in the reports were marked using the following marking scheme;

Marking scheme: very poor - 1, poor- 2, satisfactory -3 , good -4 , very good -5 .

Marks obtained for each criterion under a section analyzed were added to obtain a total mark. The average of the total mark for each section was again graded according to the same marking scheme above.

Example: For the section 'basic information' 3x5 $=15$ if all 03 criteria were graded as very good, and the average mark would be 15/03 $=05$. The grade obtained by the section would be very good.

\section{Results}

The grades thus obtained for each section was plotted against the number of students.

(Chart no. 01).

Chart 1: number of students and the grade obtained under each section $A$ - $F$

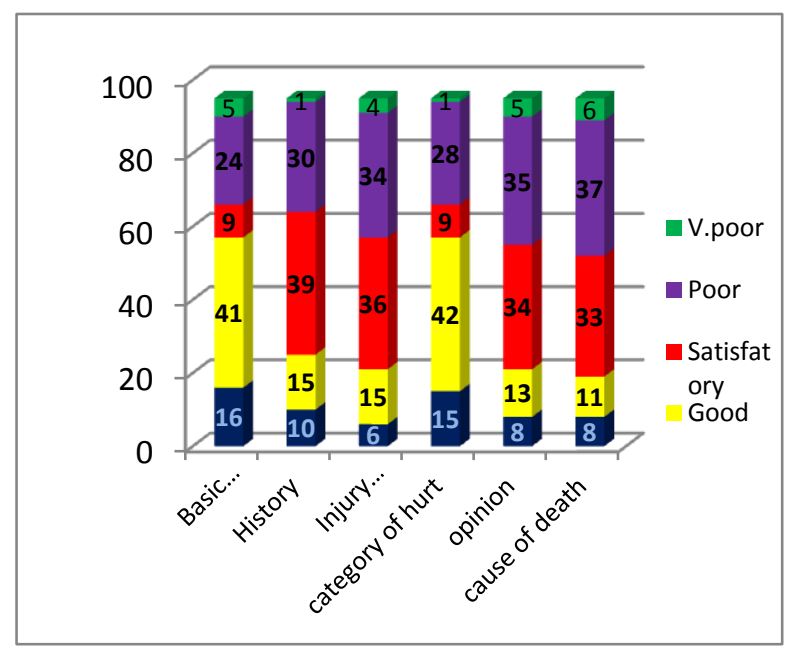

Grades of satisfactory and above (good or very good) were regarded as having achieved competence.
Individual sections with the performance of students

\section{Chart no. 2A: Basic information}

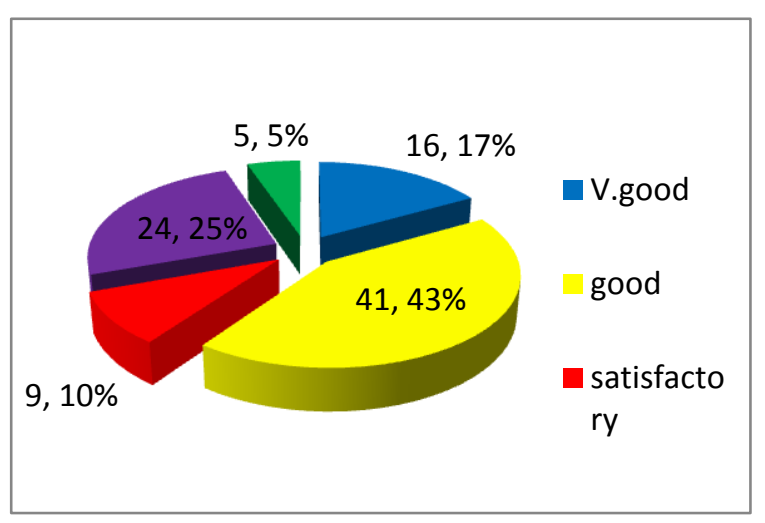

Chart no. 2B: History

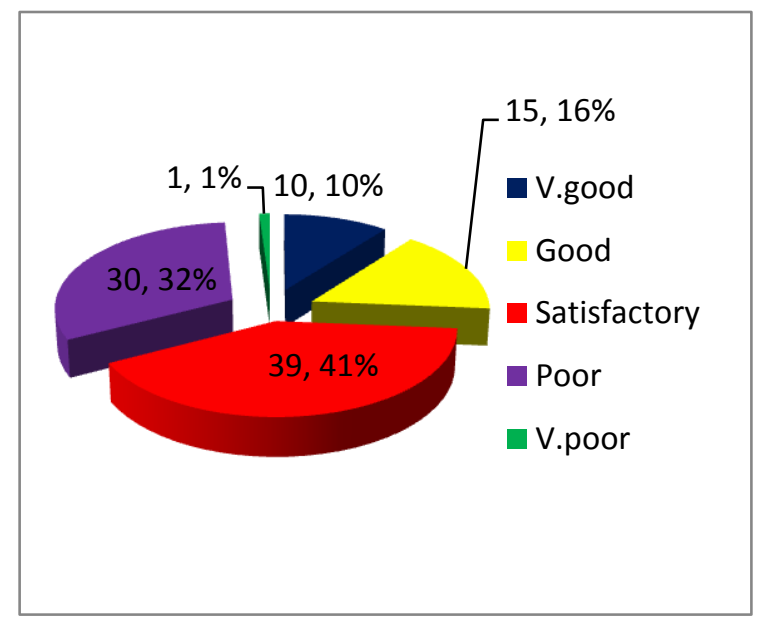

Chart no. 2C: Injury description

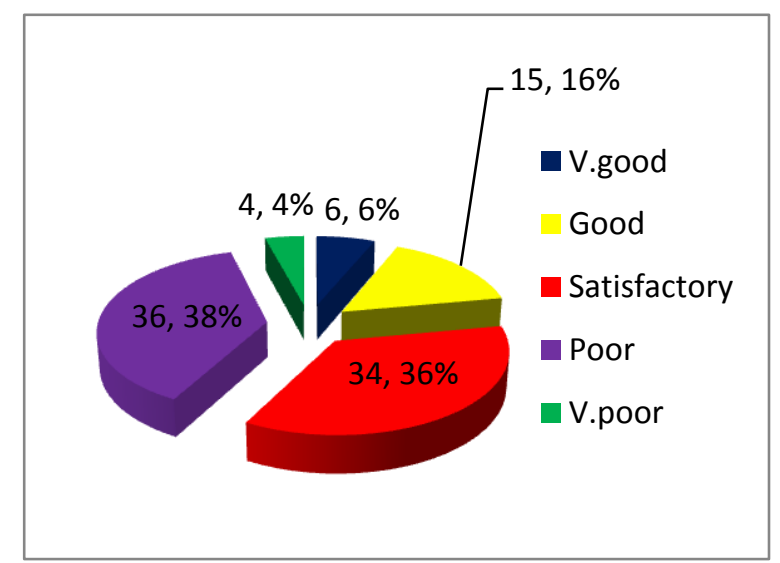


Chart no. 2D: Category of hurt

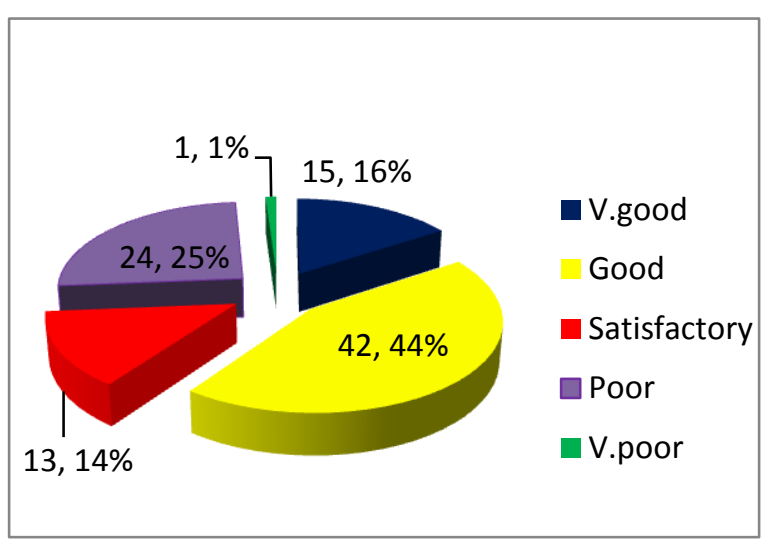

Chart no. 2E: Opinion

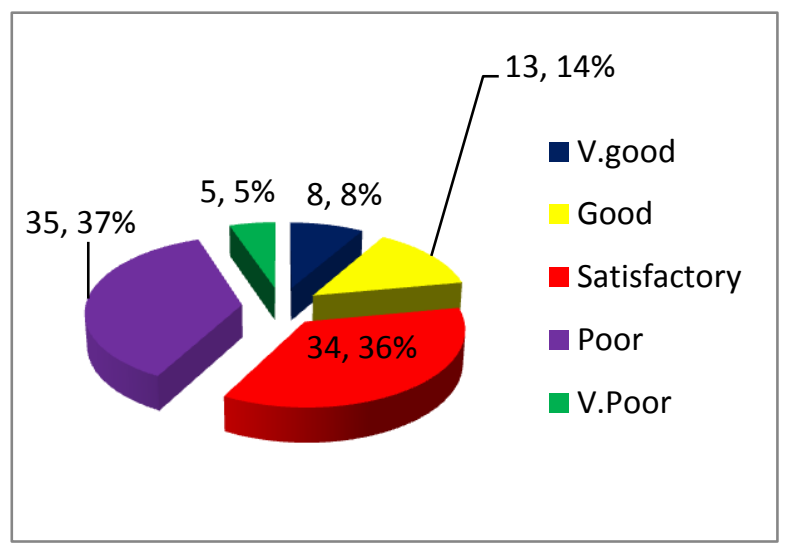

Chart no. 2F: Cause of death

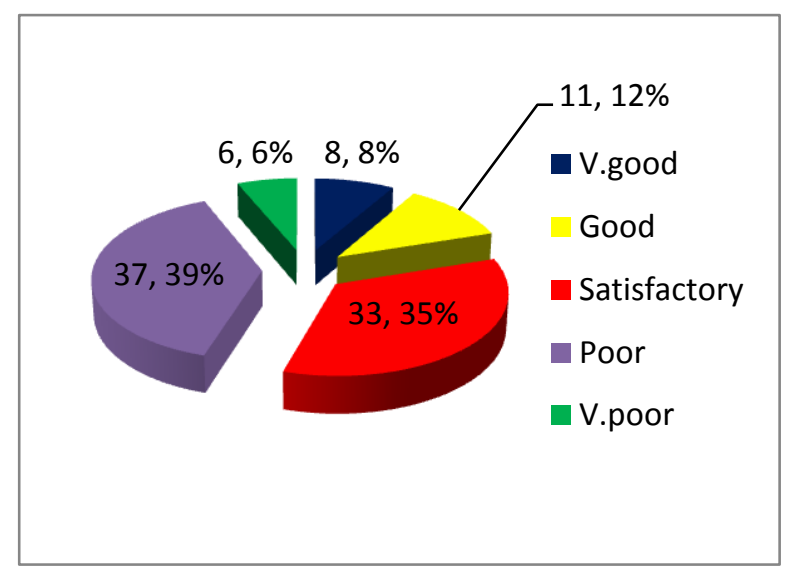

In the basic information section $66(70 \%)$ of students were competent, for history a competence of $64(67 \%)$ had been achieved. Injury description had a lower success rate of $55(58 \%)$. In filling the category of hurt, $70(74 \%)$ of students showed competence. The opinion section analysis showed a competence of only $55(58 \%)$ and the formulation of cause of death only $52(55 \%)$.

\section{Discussion}

Examinations at the end of a clinical appointment may fail to assess the skills and knowledge acquired directly from clinical experience [4]. Therefore it is important to make sure that students have attained the required level of competency at the end of the clinical appointment.

Basic information, history, injury description, category of hurt, opinion and cause of death were the sections assessed in this study. All these students did the appointment prior to the medico-legal module lectures and therefore they lacked the basic theoretical knowledge in Forensic Medicine. This lack makes it difficult to impart necessary skills and competencies under the above analysed criteria. Within a short period of two weeks basic theory as well as practical skills have to be imparted to students. In spite of this we have been able to achieve a fairly good outcome as the majority of students have achieved grades ranging from satisfactory to very good relevant to all criteria.(see chart $01)$. However, the important finding is that out of 95 students a significant number of students have performed poorly. The percentage performance of poor and very poor for each of the criteria varied from $26 \%$ (for category of hurt) to $45 \%$ (for cause of death). The criteria where competence was least achieved was for a crucial opinion, the cause of death where $45 \%$ showed poor or very poor performance. Forty two percent showing a poor or very poor performance for injury description is also a significant finding. Therefore, teachers cannot be happy with this state as in many criminal trials court system relies heavily upon medical evidence. Poor injury description coupled with 
cause of death opinion that fall below standard in the reports are likely to result in miscarriage of justice in the corresponding cases.

The quality of the learning activities employed, determines to a large extent the quality of the learning results achieved [5]. Therefore teaching should be geared to produce a higher percentage of competent graduates.

Reforming clinical education is such a critical issue that we need more research and innovation [6]. In response to the findings in our analysis, we recommend several reforms in the Forensic medicine curriculum. Well-organized and strategic learning styles appear to influence the benefits of increased clinical exposure [7].To achieve this we need to rethink the structure of our clinical appointment and also the positioning of it within the curriculum. The medico legal module is completed in four weeks (approximately 50 hours of lectures and other activities); this can be used to the advantage of the clinical teaching. If students are able to do the appointment after the conduct of the medico-legal module they will find it easy to grasp the clinical concepts. Much of the time of the appointment can then be devoted to imparting practical skills rather than teaching theory to the students. We propose that this measure will contribute towards improving the competencies.

Closer supervision and providing feedback to students regarding practical skills can contribute to better achievement of competencies [8], which is a point to consider during the appointment. Another alternative is to consider increasing the time duration of the appointment to one month. Then the students have more time to gain theoretical knowledge necessary to master the practical skills and attain the competencies. However this might create logistical difficulties as it affects the clinical roster of the Faculty which is usually prepared at the beginning of the course for each batch.

Another option would be to have a larger group of students, for example combining two groups and run it over one month. The possible problems could be inadequate space, number of academic staff and availability of consultants; furthermore, lack of one to one attention could hinder the achievement of competencies.

\section{Conclusions}

Reforms are necessary to achieve a better outcome in the clinical appointment. Out of the proposed options, getting the students to do the appointment after completing the medico legal module appears to be the more plausible; logistics have to be discussed in the relevant forum, that is the curriculum development and evaluation committee of the Faculty. We hope that this analytical study enlightens the authorities to take this seriously and do this change in order to achieve the competencies at the end of the clinical appointment in Forensic Medicine.

\section{Limitations}

If the same study was done with students who followed the appointment after the medicolegal module the results could have been compared with the present study. This was not possible as only few groups did the appointment after completion of the module during the initial stages of the new curriculum about two decades ago.

\section{References}

1. Ponnamperuma G, Ker J, Davis M. Medical professionalism: teaching, learning, and assessment; South East Asian Journal of Medical Education, Inaugural issue 2006;Vol. 1. No. 1:42-48

2. McLeod $P$ J, Steinert $Y$, Meagher $T$, Schuwirth L, Tabatabai D, McLeod AH. The acquisition of tacit knowledge in medical education: learning by doing Medical Education 2006; 40: 146-149.

3. Abeyasinghe NL Teaching of forensic medicine in the undergraduate curriculum in Sri Lanka: bridging the gap between theory and practice; Medical Education 2002; 36:1089. 
4. McManus IC, Richards $P$, Winder BC, Sproston KA; Clinical experience, performance in final examinations, and learning style in medical students: prospective study.BMJ Vol 316:31 January 1998, 345-349

5. Marambe K N, Edussuriya D H, Indika P D, Somaratne S, Piyaratne C, Do medical students who claim to be using deep learning strategies perform better at the Forensic Medicine examination? South East Asian Journal of Medical Education, Medical Education 2009, 3(1):25-30

6. Snadden D. Clinical education: context is everything. Medical Education 2006; 40: 97-98

7. Martin IG, Stark P, Jolly B D; Benefiting from clinical experience: the influence of learning style and clinical experience on performance in an undergraduate objective structured clinical examination. Educ. 2000 Jul; 34(7):530-4

8. DaelmansH E M, OvermeerR $M$, Van der Hem-StokroosH H, ScherpbierA J J A, StehouwerC D A, Van der VleutenC P M; Intraining assessment: qualitative study of effects on supervision and feedback in an undergraduate clinical rotation. Medical Education 2006; 40: 51-58.

\section{Contribution of authors}

Design to the study - AM, JP

Analysis of the data - AM, RS

Interpretation of the results - AM, JP

Writing the manuscript - AM, JP

Revising the manuscript- JP 